\title{
Simulação dos estoques de Carbono e Nitrogênio pelo Modelo Century em Latossolos, no Cerrado Brasileiro'
}

\author{
Simulation using the Century Model of the Carbon and Nitrogen Stocks in Latosols \\ of the Brazilian Cerrado
}

\author{
Beno Wendling ${ }^{2}$, Ivo Jucksch ${ }^{3}$, Eduardo de Sá Mendonça ${ }^{4}$, Risely Ferraz de Almeida ${ }^{2 *}$ e Ramon Costa \\ Alvarenga ${ }^{5}$
}

\begin{abstract}
RESUMO - O uso de modelos matemáticos pode ser útil para o entendimento das alterações do uso e manejo do solo e fornecem subsídios para testar cenários futuros, possibilitando desenvolver estratégias de manejo menos impactantes ao meio ambiente. Os objetivos deste trabalho foram: (a) usar o modelo Century v4.5 para simular os efeitos dos usos e manejos sobre os estoques de carbono e nitrogênio do solo em diferentes compartimentos, (b) comparar os estoques medidos e simulados pelo Century, e (c) testar impacto de cenários futuros até o ano de 2100. Os tratamentos avaliados foram Pinus, plantio direto e plantio convencional, com histórico das áreas até o momento da coleta de solo (2004). Para o Pinus foram testados três cenários futuros, um deles simulando o mesmo manejo adotado até o momento da coleta de solo, outro reduzindo os eventos de fogo, além do uso sem preparo do solo para o replantio. Para o plantio direto e plantio convencional, simularam-se dois cenários futuros, um com rotação milho/soja e outro com monocultura de milho. O modelo Century foi sensível às mudanças de manejo adotadas, os compartimentos mais lábeis apresentam maior sensibilidade (ativo e lento), do que o mais estável (passivo). Em relação ao estoque de $\mathrm{C}$, o modelo simulou estoques próximos aos medidos no campo, com um erro mínimo de $0,36 \%$. Para os estoques de $\mathrm{N}$, os valores simulados apresentaram erro de 5,71\% para os compartimentos mais lábeis. Os cenários futuros mostraram a importância de se evitar queimadas no Pinus e o uso de monocultivo.
\end{abstract}

Palavras-chave: Estoques de nitrogênio. Estoques de carbono. Sequestro.

ABSTRACT - The use of mathematical models can be useful for understanding the changes in the use and management of soil and provide aid in testing future scenarios, making it possible to develop management strategies which have less impact on the environment. The objectives of this study were: (a) to apply the Century Model v4.5 in order to simulate the effects of usages and managements on carbon stocks and soil nitrogen in different compartments; (b) compare both the observed stocks and those simulated by the Century Model; (c) to test the impact of future scenarios until the year 2100. The treatments evaluated were of Pine, under both no-tillage and conventional tillage, using historical data from the areas up until when the soil was sampled (2004). For the pine, three future scenarios were tested, one by simulating the management adopted up to the time the soil was sampled, another by reducing the fire events, as well as by soil usage without any preparation when replanting. For both no-tillage and conventional tillage, two future scenarios were simulated: one with corn and soybean rotation, and the other with a monoculture of corn. The Century model was sensitive to the changes in management which were adopted, the more labile compartments showing greater sensitivity (the active and the slow) than the most stable (passive). In relation to stocks of $\mathrm{C}$, the model simulated values close to those measured in the field, with a minimum error of $0.36 \%$. For stocks of $\mathrm{N}$, the simulated values showed an error of $5.71 \%$ for the more labile compartments. For pine, the future scenarios demonstrated the importance of preventing fires, and the use of monocultures.

Key words: Stocks of nitrogen. Stocks of carbon. Sequestration.

\footnotetext{
*Autor para correspondência

'Recebido para publicação em 12/12/2012; aprovado em 26/12/2013

Parte da Tese de Doutorado do primeiro autor apresentada na Universidade Federal de Viçosa

${ }^{2}$ Instituto de Ciências Agrárias - Iciag, Universidade Federal de Uberlândia-UFU, Campus Umurama, Uberlândia-MG, Brasil, 38.400-902,

beno@iciag.ufu.br, rizely@gmail.com

${ }^{3}$ Departamento de Solos, Universidade Federal de Viçosa-UFV, Viçosa-MG, Brasil, ivo@ufv.br

${ }^{4}$ Departamento de Produção Vegetal, Universidade Federal do Espírito Santo-UFES, Alegre-ES, Brasil, eduardo.mendonca@ufes.br

${ }^{5}$ Empresa Brasileira de Pesquisa Agropecuária, Centro Nacional de Pesquisa de Milho e Sorgo (EMBRAPA/CNPMS), Sete Lagoas-MG, Brasil, ramon.alvarenga@embrapa.br
} 


\section{INTRODUÇÃO}

Com o advento da agricultura, o Cerrado brasileiro passou a ter importante papel na produção de alimentos. De maneira geral apresentam solos pobres em cátions trocáveis e boas características físicas, tais como relevo plano, perfil profundo, boa porosidade e estabilidade de agregados (WENDLING, 2007). Contudo, com o uso agrícola estes solos apresentaram melhorias nas propriedades químicas e as físicas foram gradativamente degradadas.

$\mathrm{O}$ alto grau de intemperismo desses solos (predominância de argilas de baixa atividade) os torna muito dependentes da matéria orgânica para manter adequado funcionamento e sustentabilidade (SILVA; MENDONÇA, 2007). Assim, deve ser dada prioridade na busca de sistemas de produção que permitam preservar essa matéria orgânica, que tem papel fundamental na manutenção das propriedades físicas, químicas e biológicas dos solos. Neste sentido, ao converter novamente as áreas agrícolas em florestas, com o passar das décadas, ocasionam um aumento significativo das quantidades de C do solo (HARRISON et al., 1995).

Tem-se dado muita importância à incorporação de $\mathrm{C}$ (carbono) ao solo para mitigar o aumento de $\mathrm{CO}_{2}$ (dióxido de carbono) na atmosfera, mas a importância maior está na melhoria das qualidades emergentes que se consegue com esse "sequestro de C". O uso de modelos matemáticos tem sido proposto para estudar o comportamento de diferentes usos e práticas de manejo em relação à dinâmica de matéria orgânica no solo. Entre os modelos mais usados, está o Century, que foi utilizado em ecossistemas tropicais (CERRI et al., 2003; LEITE e MENDONÇA, 2003; LEITE et al., 2004a) e subtropicais (FERNANDES, 2002), apresentando boa capacidade para simular os efeitos de diferentes usos e manejos.

O modelo Century foi concebido em 1987 (PARTON et al., 1987), e a partir de então vem sendo amplamente testado e usado, fato que permitiu que a aplicabilidade do modelo evoluísse. A versão inicial permitia apenas a simulação para pastagens, as versões atuais permitem realizar simulações para as mais diversas condições, desde florestas plantadas, pastagens até culturas anuais.

Esse estudo teve três objetivos: (a) usar o modelo Century v4.5 para simular os efeitos dos usos e manejos do solo sobre os estoques de $\mathrm{C}$ e $\mathrm{N}$ em diferentes compartimentos, (b) comparar os resultados observados no campo por meio de métodos laboratoriais e os obtidos nas simulações com o modelo, e (c) testar o impacto de cenários futuros até o ano de 2100.

\section{MATERIAL E MÉTODOS}

\section{Área de estudo e amostragem}

A área de estudo pertence à Empresa Brasileira de Pesquisa Agropecuária - EMBRAPA e está localizada no município de Sete Lagoas/MG, Brasil (latitude $19^{\circ} 28^{\prime}$, longitude $-44^{\circ} 15^{\prime}$ e altitude de $732 \mathrm{~m}$ ). O solo do local é classificado como Latossolo Vermelho típico, com relevo suave ondulado e textura muito argilosa. $\mathrm{O}$ clima da região é classificado como Aw (clima de savana com inverno seco), segundo a classificação proposta por Köppen, com temperatura média anual de $20,9{ }^{\circ} \mathrm{C}$, precipitação pluviométrica média anual de $1.320 \mathrm{~mm}$ e Cerrado como vegetação nativa.

A amostragem do solo foi realizada em julho de 2004. Em todos os tratamentos, inclusive o Cerrado Nativo (CE), foram coletadas cinco amostras compostas para cada camada, 0,0-0,10 m e 0,1-0,2 m. Contudo, como o Modelo Century avalia apenas a camada de 0,0-0,2 m fez-se a somatória dos valores obtidos nas camadas obtendo um único valor.

Cada amostra composta foi obtida pela mistura de dez amostras simples. Parte do material coletado foi mantido sob refrigeração para posterior determinação do $\mathrm{C}$ e $\mathrm{N}$ da biomassa microbiana. Para as demais análises utilizou-se a terra fina seca ao ar (TFSA).

\section{Análises físico/químicas}

O carbono orgânico total (COT) foi determinado via combustão úmida (YEOMANS; BREMNER, 1988). Para quantificação do nitrogênio total (NT), as amostras foram submetidas à digestão sulfúrica com posterior destilação Kjedall (TEDESCO et al., 1995).

Para liberar o $\mathrm{C}$ e $\mathrm{N}$ da biomassa microbiana para a solução extratora de $\mathrm{K}_{2} \mathrm{SO}_{4} \quad 0,5 \quad \mathrm{~mol}^{-1}$ utilizou-se o método de irradiação-extração (ISLAM; WEIL, 1998), sendo usado um forno de micro-ondas com frequência de $2450 \mathrm{MHz}$ e energia de $900 \mathrm{~W}$ durante 180 segundos (ISLAM; WEIL, 1998). O C foi quantificado via oxidação úmida (TEDESCO et $a l .$, 1995), enquanto o $\mathrm{N}$, após digestão sulfúrica, foi quantificado por destilação Kjedahl (TEDESCO et al., 1995). Corrigida a umidade, o $\mathrm{C}$ microbiano $\left(\mathrm{C}_{\mathrm{MIC}}\right) \mathrm{e}$ o $\mathrm{N}$ microbiano $\left(\mathrm{N}_{\mathrm{MIC}}\right)$ foram calculados com base na diferença das subamostras irradiadas e não irradiadas, utilizando-se um fator de conversão de fluxo (Kc) de 0,33 (SPARLING; WEST, 1988) e 0,54 (BROOKES et al., 1985) para $\mathrm{C}$ e $\mathrm{N}$, respectivamente. $\mathrm{O} \mathrm{C}_{\mathrm{MIC}}$ e $\mathrm{N}_{\mathrm{MIC}}$ foram usados para representar o compartimento de menor tempo de reciclagem no solo, ou seja, o ativo. 
A separação da fração leve livre particulada (FLLP) do solo foi realizada pelo principio da diferença de densidade e tamanho (CAMBARDELLA; ELLIOTT, 1994), em que a densidade do líquido (NaI) foi de $1,8 \mathrm{~kg} \mathrm{~L}^{-1}$ e a peneira usada para separar o material leve da solução extratora foi de $0,25 \mathrm{~mm}$ de diâmetro. O material retido na peneira foi lavado, seco a $65^{\circ} \mathrm{C}$, triturado e analisado via combustão seca em analisador Perkin Elmer series II 2400 CHNS/O. $\mathrm{O} \mathrm{C}$ e $\mathrm{N}$ contidos nesse material foram usados para representar o compartimento com tempo de reciclagem intermediária, ou seja, o lento. O compartimento com tempo de reciclagem mais longo, o $\mathrm{C} \mathrm{e} \mathrm{N}$ passivo, foi determinado por diferença: passivo $=$ totais $-($ ativo + lento).

\section{Sequência dos eventos simulados}

Na Tabela 1 são apresentadas as sequências de manejos usados nas simulações pelo Century. A derrubada do Cerrado deu início ao uso agrícola dessas áreas. O Cerrado foi desmatado e a madeira retirada, possibilitando o preparo da área para o plantio da braquiária (Brachiaria sp.), que permaneceu até 1972, ocasião em que parte dessa área foi plantada com pinus (Pinus sp.) e parte foi usada para plantio de milho no sistema convencional e posteriormente, no ano de 1994, recebeu um experimento para avaliar os sistemas de preparo convencional (PC) e direto (PD). Esses dois sistemas diferiram entre si na maneira de preparo do solo, em que PC recebeu duas operações com grade pesada, enquanto o PD manejo com herbicida dessecante (princípio ativo Gliphosate).
Para a braquiária foram simulados um evento de fogo no período seco (inverno) e 6 eventos de pastejo durante a estação chuvosa (parte da primavera, verão e parte do outono). O Pinus foi plantado e nos primeiros anos mantido limpo com uso de grade na entre linha. A partir do sexto ano, queimadas involuntárias passaram a ocorrer em média a cada dois anos.

\section{Simulação de cenários futuros}

Foram simulados cenários de manejo até o ano de 2100. Para o PIN simulou cortes a cada 30 anos para três situações de manejo. Na primeira considerou-se que o manejo seria tal como foi até o ano de 2004 (PINa), na segunda considerou-se a ausência de preparo do solo nos anos iniciais (PINb) e na terceira uma menor ocorrência do fogo (passando de queimadas bianuais para duas queimadas durante um ciclo) (PINc). Para o caso do PD e PC, duas situações foram simuladas. Na primeira considerando o monocultivo de milho (PDa e PCa) e na segunda cultivos alternados de milho e soja (PDb e $\mathrm{PCb}$ ).

\section{Validação do modelo}

Para o funcionamento do modelo Century utilizou-se 3 submodelos, o da produção vegetal, o da água e da dinâmica de matéria orgânica do solo. Os dois primeiros alimentaram o terceiro, gerando os dados necessários em relação à umidade e temperatura do solo, entradas e saídas de nutrientes pelas culturas, quantidade e a qualidade de resíduos vegetais produzidos (LEITE; MENDONÇA, 2003).

O submodelo da matéria orgânica do solo foi divido em compartimentos (ativo, lento e passivo), com base no

Tabela 1 - Sequência de culturas usadas na simulação pelo modelo Century 4.5

\begin{tabular}{|c|c|}
\hline Tratamento & Sequências de manejo \\
\hline \multirow{4}{*}{$\mathrm{PC}$} & - 1968: desmatamento (retirada da madeira e posterior uso de fogo) \\
\hline & - 1969 até 1972: pastagem de braquiária com pastejo na estação chuvosa \\
\hline & - 1973 até 1994: plantio convencional de milho \\
\hline & - 1995 até 2004: condução de experimento com plantio convencional de milho* \\
\hline \multirow{4}{*}{ PD } & - 1968: desmatamento (retirada da madeira e posterior uso de fogo) \\
\hline & - 1969 até 1972: pastagem de braquiária com pastejo na estação chuvosa \\
\hline & - 1973 até 1994: plantio convencional de milho \\
\hline & - 1995 até 2004: condução de experimento com plantio direto de milho e soja* \\
\hline \multirow{3}{*}{ PIN } & - 1968: desmatamento (retirada da madeira e posterior uso de fogo) \\
\hline & - 1969 até 1972: pastagem de braquiária com pastejo na estação chuvosa \\
\hline & - 1973: plantio do Pinus (ainda se encontrava na área em 2004) \\
\hline
\end{tabular}

\footnotetext{
* O plantio da soja foi realizado somente em 1993
} 
seu tempo de reciclagem e taxas de decomposição. $\mathrm{O}$ ativo representado pela biomassa microbiana e produtos derivados, com tempo de reciclagem de até 5 anos. $\mathrm{O}$ lento representado pela matéria orgânica leve, derivada do material vegetal das culturas ou da aplicação orgânica ao solo, com tempo de reciclagem estimado entre 20 e 40 anos. O passivo representado pelo material muito resistente à decomposição e protegido física e quimicamente pelo solo, podendo alcançar tempos de reciclagem entre 200 a 500 anos (PARTON et al., 1987).

Para as simulações de equilíbrio (6000 anos) para a área de Cerrado nativo $(\mathrm{CN})$, utilizaram-se os dados de entrada no modelo com as variáveis do local, como textura, densidade e clima (Tabela 2). Criou-se um arquivo apropriado para realizar a simulação de equilíbrio para a vegetação do tipo Cerrado. Tanto para o Cerrado, Pinus e demais culturas, o modelo foi rodado para ajustar o submodelo de produção de planta, onde a produção primária (Cerrado e Pinus) ou produtividades (culturas anuais e pastagens) foram mantidas de acordo com dados de campo ou literatura, só depois o modelo foi usado para simular a dinâmica de $\mathrm{C}$ e $\mathrm{N}$ no solo. Para cada um dos tratamentos, o modelo simulou a derrubada do $\mathrm{CN}$ e a conversão desses para os tratamentos estudados, estimando os estoques de $\mathrm{C}$ e $\mathrm{N}$ para cada compartimento ao longo dos anos (1968 até 2004).

A simulação para os tratamentos foi iniciada com os dados gerados pela simulação de equilíbrio. Os valores estimados pelo modelo para o mês de julho foram comparados com os obtidos no campo via métodos laboratoriais, permitindo testar a validade do modelo. A partir do erro padrão da média foi possível comparar os valores medidos dos simulados.

\section{RESULTADOS E DISCUSSÃO}

\section{Simulação de equilíbrio}

Para a simulação de equilíbrio foram necessárias algumas alterações no arquivo de variáveis fixas do modelo (FIX.100), para que as taxas de decomposição dos compartimentos se ajustassem aos do CN. Sem esse ajuste não seria possível rodar o modelo para condições tropicais, uma vez que este foi concebido e validado para situações de clima temperado. Outro arquivo que necessitou de ajustes foi o de árvore (TREE.100), onde a produção primária foi ajustada de acordo com o encontrado no Cerrado. Depois destes ajustes feitos o modelo foi rodado simulando um período de 10.000 anos, possibilitando a estabilização dos compartimentos.

A partir de 6000 anos os valores se estabilizaram (Tabela 3). O COT estabilizou em 52,75 $\mathrm{Mg} \mathrm{ha}^{-1}$, muito semelhante às medidas encontradas no Cerrado via análises laboratoriais, $52,94 \mathrm{Mg} \mathrm{ha}^{-1}$. Os compartimentos de $\mathrm{C}$ simulados também foram semelhantes à realidade de campo, verificando que, o modelo está apto a rodar cenários específicos para $\mathrm{C}$, uma vez que os compartimentos, bem como o COT foram semelhantes aos valores observados no Cerrado.

Para NT o modelo foi menos preciso, apresentando estoques de 3,5 e $3,3 \mathrm{Mg} \mathrm{ha}^{-1}$ entre os dados simulados e medidos, respectivamente, com erro de $10 \%$ (Tabela 3 ). O modelo superestimou os compartimentos lento e passivo e subestimou o ativo. Contudo, os valores simulados apresentam um erro de $5,71 \%$, não alterando a relação entre os compartimentos de $\mathrm{C}$ e $\mathrm{N}$ no solo sob Cerrado.

Tabela 2 - Principais variáveis de entrada usadas para as simulações com o modelo Century 4.5

\begin{tabular}{lc}
\hline \multicolumn{1}{c}{ Variáveis } & Valores \\
\hline Areia $\left(\mathrm{g} \mathrm{g}^{-1}\right)$ & 0,14 \\
Silte $\left(\mathrm{g} \mathrm{g}^{-1}\right)$ & 0,13 \\
Argila $\left(\mathrm{g} \mathrm{g}^{-1}\right)$ & 0,73 \\
Densidade do solo $\left(\mathrm{g} \mathrm{cm}^{-3}\right)$ & 0,83 \\
pH $\left(\mathrm{H}_{2} \mathrm{O}\right)$ & 4,57 \\
Precipitação mensal** & 28,$90 ; 16,12 ; 13,26 ; 5,28 ; 2,61 ; 1,03 ; 1,45 ; 1,01 ; 3,29 ; 11,57 ; 22,72 ; 26,63$ \\
$\mathrm{~T}^{\circ} \mathrm{C}$ média mensal mínima* & 18,$20 ; 18,10 ; 17,90 ; 16,10 ; 13,70 ; 11,50 ; 11,10 ; 16,60 ; 14,80 ; 17,70 ; 17,70 ; 18,10$ \\
$\mathrm{~T}^{\circ} \mathrm{C}$ média mensal máxima* & 28,$90 ; 29,70 ; 29,00 ; 27,50 ; 25,30 ; 24,20 ; 24,50 ; 25,60 ; 28,70 ; 28,90 ; 28,60 ; 28,20$ \\
\hline * Temperatura em Graus Celsius $\left(\mathrm{T}^{\circ} \mathrm{C}\right)$, média mensal mínima e máxima dos meses de janeiro a dezembro, respectivamente; ** Precipitação
\end{tabular}


Tabela 3 - Valores simulados e medidos para carbono orgânico total (COT) e nitrogênio total (NT) nos compartimentos ativo, lento e passivo em solos para o Cerrado (simulação de equilíbrio), em Sete Lagoas/MG

\begin{tabular}{lcccc}
\hline \multirow{2}{*}{ Compartimentos $^{1}$} & ----------Estoques de $\mathrm{C}\left(\mathrm{Mg} \mathrm{ha}^{-1}\right)$---------- & ---------Estoques de NT $\left(\mathrm{Mg} \mathrm{ha}^{-1}\right)$---------- \\
\cline { 2 - 5 } & \multicolumn{1}{c}{ Simulado } & Medido & Simulado & Medido \\
\hline Ativo & 0,98 & $0,98(0,07)$ & 0,09 & $0,11(0,01)$ \\
Lento & 3,84 & $3,89(0,37)$ & 0,15 & $0,12(0,02)$ \\
Passivo & 47,93 & $48,07(2,06)$ & 3,26 & $3,07(0,15)$ \\
Total & 52,75 & $52,94(2,29)$ & 3,50 & $3,30(0,16)$ \\
\hline
\end{tabular}

${ }^{1}$ Valores entre parênteses referem-se ao erro padrão da média

\section{Simulação da dinâmica de C e N}

A partir dos valores da simulação de equilíbrio, procedeu-se a simulação dos cenários apresentados na Tabela 2. Na Figura 1 é observada a dinâmica do COT e dos compartimentos ativo, lento e passivo a partir dos valores da simulação de equilíbrio até o final do ano de 2004. Nesse período o modelo simulou as mudanças no uso e manejo adotadas para cada tratamento.
Com a derrubada do Cerrado,1969, e preparo do solo para implantação da pastagem de braquiária, os estoques dos compartimentos $\mathrm{C}$ ativo e $\mathrm{C}$ lento simulados aumentaram consideravelmente. Esse comportamento é comum (STEVENSON, 1994), pois com a derrubada do Cerrado, foi retirado o material vegetal de maior diâmetro, permanecendo no campo parte dos restos de galhos finos, folhas e serrapilheira

Figura1 - Variação dos estoques de carbono orgânico total (COT) e compartimentos passivo (C passivo), lento (C lento) e ativo (C ativo) estimados pelo modelo Century v4.5 para os tratamentos plantio convencional (PC) plantio direto (PD) e plantação de PINUS, em Sete Lagoas/MG
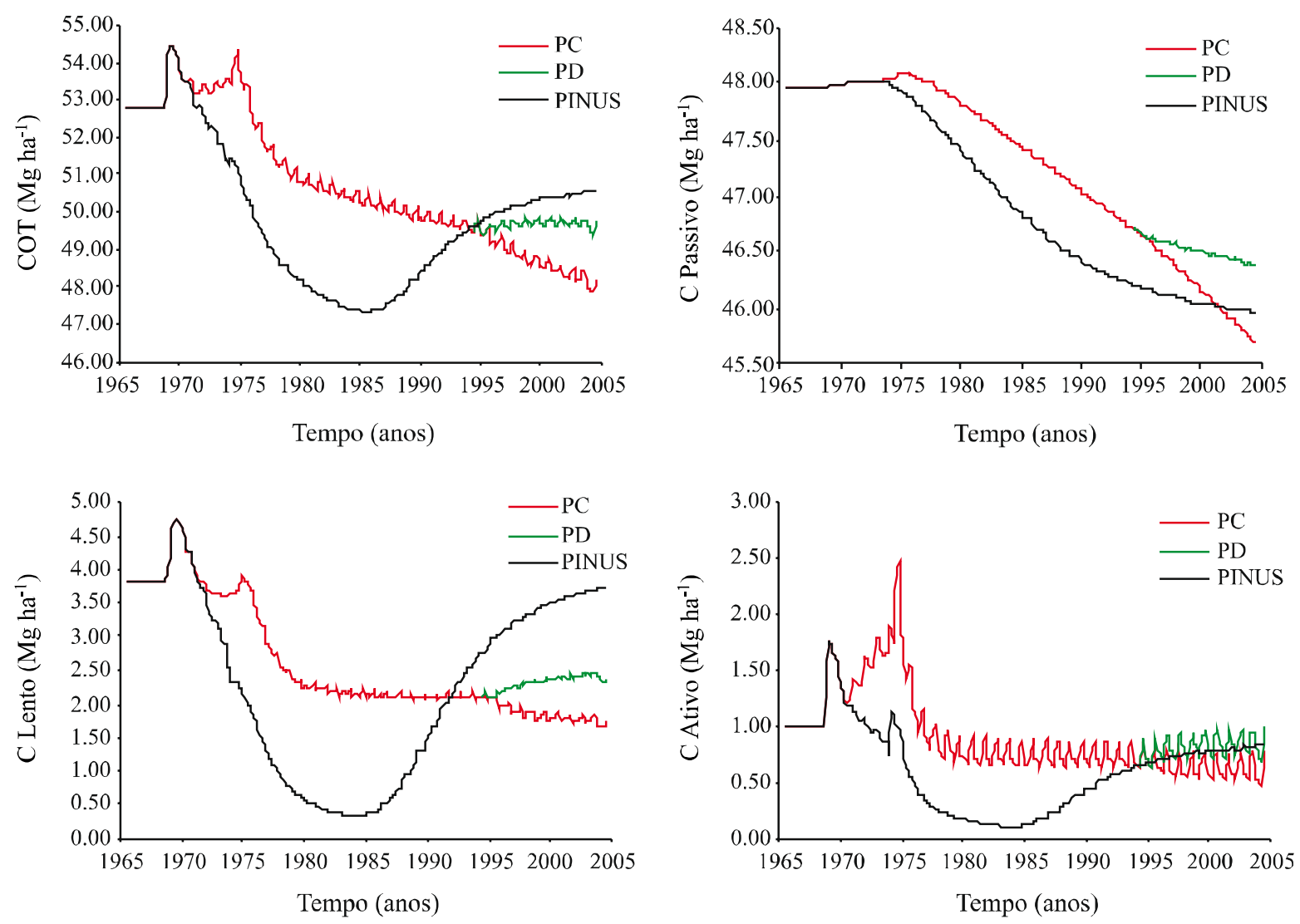
depositada na superfície, que são incorporados ao perfil do solo. Porém, no ano seguinte, os estoques voltam a diminuir, devido ao efeito da decomposição desse material, que é acelerada pelo revolvimento do solo por ocasião da implantação da cultura da braquiária. Os dados de COT seguiram o comportamento dos compartimentos mais lábeis (ativo e lento) e, devido a estabilidade química e física, o compartimento passivo não expressou essa mudança no manejo.

Até 1973 todos os tratamentos foram iguais, ou seja, cultivo de braquiária para pastejo intensivo. Neste período os estoques de COT se mantiveram acima dos estoques observados para o Cerrado, pois o solo não foi mais revolvido e o pastejo não foi instensivo a ponto de comprometer a entrada de material vegetal. Somente o estoque de $\mathrm{C}$ lento foi menor que o observado no Cerrado. No final deste período, com o preparo do solo para implantação das culturas anuais e Pinus, houve rápido aumento seguido de diminuição nos estoques de C para todos os compartimentos, porem menos perceptível para o C passivo.
A partir de 1973 foi iniciado o cultivo de milho nos tratamentos PC e PD (até 1994 o cultivo convencional era adotado nestes tratamentos). Até 1994, os estoques de todos os compartimentos sofreram diminuição. $\mathrm{O}$ PC ocasiona perda de $\mathrm{C}$ no solo devido à desagregação da estrutura e aumento da aeração, que favorecem a oxidação do material orgânico (LOBEL et al., 2001). Em outros trabalhos usando o modelo Century realizados no Brasil, esse mesmo comportamento foi observado (LEITE et al., 2004a; LEITE et al., 2004b).

No ano de 1994 os estoques de COT e dos compartimentos ativo, lento e passivo para os tratamentos com culturas anuais (PC e PD) foram 49,44; 0,70; 2,10 e 46,65 $\mathrm{Mg} \mathrm{ha}^{-1}$, respectivamente. A partir deste ano estes dois tratamentos começaram a se diferenciar quanto aos estoques de $\mathrm{C}$ devido à mudança imposta no manejo. Em 2004, o PD apresentou estoques maiores em todos os compartimentos em relação ao PC. Esse aumento representou $1,52 \mathrm{Mg} \mathrm{ha}^{-1}$ para COT, evidenciando a capacidade do PD em melhorar ou manter os estoques de $\mathrm{C}$, contribuindo desta forma para a melhoria da qualidade

Figura 2 - Variação dos estoques de nitrogênio total (NT) e compartimentos passivo (N passivo), lento (N lento) e ativo (N ativo) estimados pelo modelo Century v4.5 para os tratamentos plantio convencional (PC) plantio direto (PD) e plantação de PINUS, em Sete Lagoas/MG
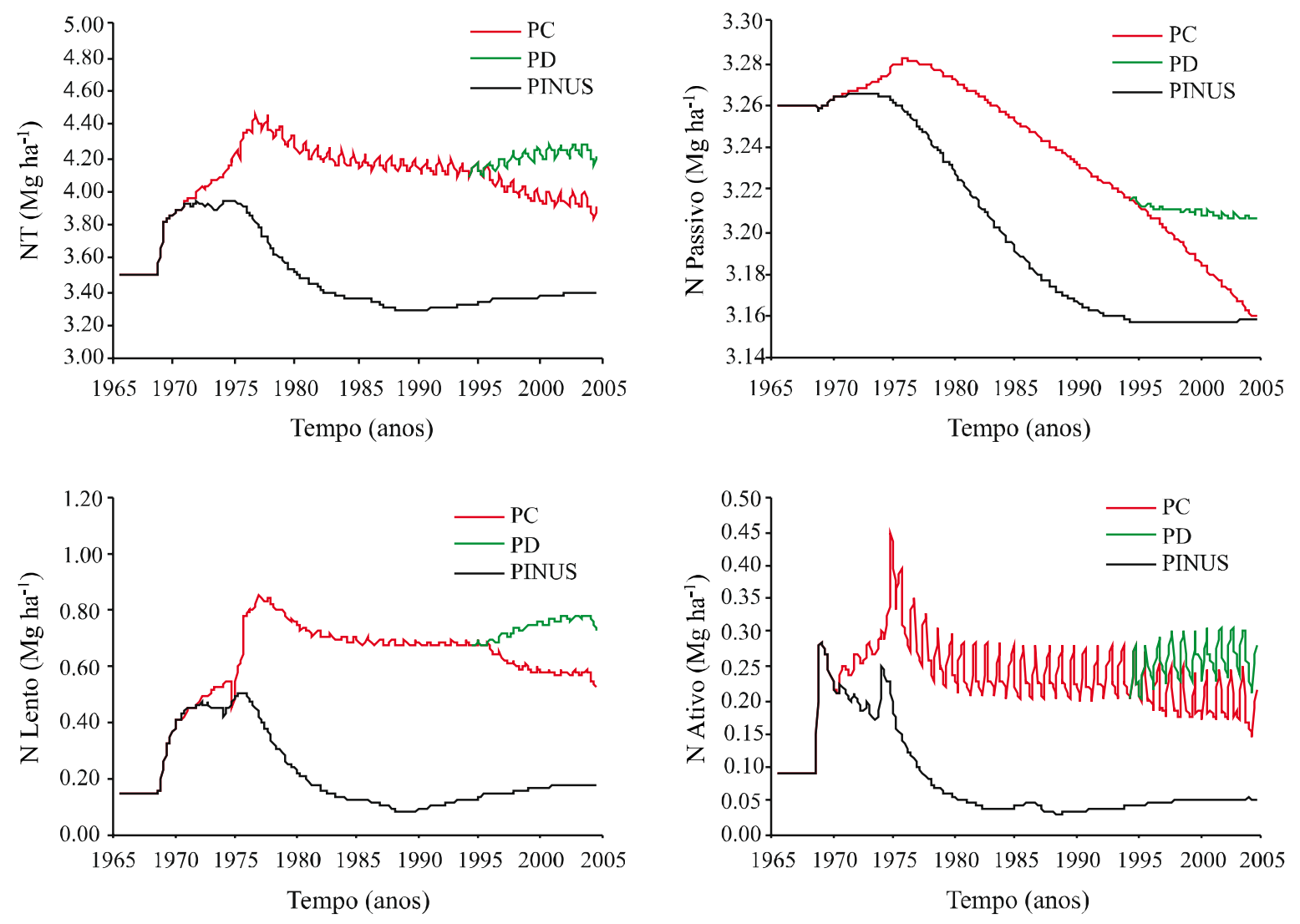
do solo. Comportamento semelhante também foi obtido usando o mesmo modelo sob condições tropicais após 19 anos de experimento (LEITE et al., 2004b), onde a diferença em favor do PD em relação ao PC foi de $4,5 \mathrm{Mg}$ ha $^{-1}$. Esses resultados evidenciam a capacidade do modelo Century em simular o impacto das mudanças do manejo do solo sobre os estoques de $\mathrm{C}$ em condições tropicais.

O compartimento passivo não apresentou recuperação com o $\mathrm{PD}$, no entanto, este foi superior $(0,68$ $\mathrm{Mg} \mathrm{ha}^{-1}$ ) em relação ao PC. Mais de $90 \%$ de todo o C está no compartimento passivo, evidenciando o caráter argiloso deste solo, que propicia grande proteção química e coloidal ao C (SIX et al., 2002). No compartimento lento e ativo os estoques de $\mathrm{C}$ aumentaram após a adoção do $\mathrm{PD}$, mas foram inferiores aos medidos em $\mathrm{CN}$.

O PIN aumentou os estoques de C após 12 anos de plantio. A perda de $\mathrm{C}$ neste tratamento foi maior em relação às culturas anuais no início do cultivo, mas depois do $12^{\circ}$ ano os estoques reagiram, superando os observados no PC. A intensa perda de $\mathrm{C}$ no início do desenvolvimento do PIN foi devido ao uso de grade nos primeiros anos (até o quarto ano) e também pelo fato da adição de material orgânico ao solo ter sido mínima, uma vez que essa cultura não perde as acículas na fase jovem. Após o quinto ano, esta área foi afetada por fogo acidental (muito comum em regiões de Cerrado) a cada dois anos em média, o que também contribuiu para o declínio dos estoques de C. Após o $12^{\circ}$ cultivo, o sistema radicular está bem desenvolvido com renovação constante, favorecendo o aumento dos estoques de $\mathrm{C}$ nos compartimentos ativo e lento, refletindo também na melhoria do COT. Somente o compartimento passivo não apresentou sinais de recuperação, no entanto, as perdas passaram a ser menores com o avanço da idade da cultura.

Na Espanha, em plantações de Pinus radiata, sobre antiga área de cultivo com cereais e outra sobre uma antiga área de vinhedos, também foi simulado pelo modelo Century perda de COT para a camada de 0,0 a 0,2 m nos primeiros anos após o plantio, apresentando melhora nos estoques a partir do quinto ano (ROMANYA et al., 2000). Esses autores também concluíram, via simulações com o Century, que solos sob plantações de Pinus radiata possuem maior potencial para o sequestro de $\mathrm{C}$ no solo em relação a florestas nativas da região (Quercus ilex).

$\mathrm{O}$ comportamento da dinâmica dos estoques de $\mathrm{N}$ foi muito semelhante aos observados para $\mathrm{C}$ em relação aos tratamentos (Figura 2). Para o PD e PC o modelo simulou valores maiores que os observados no Cerrado. $\mathrm{A}$ adição de $\mathrm{C}$ ao solo se deu unicamente via adição de restos vegetais e a de $\mathrm{N}$ ocorreu via adição de adubos e fixação biológica (no caso da soja), favorecendo um acúmulo maior ao longo do tempo, o que no caso do $\mathrm{C}$ não aconteceu.

\section{Comparação entre valores medidos e simulados}

Os valores para estoques de $\mathrm{C}$ medidos e os simulados pelo Century foram semelhantes (Tabela 4). As diferenças para os estoques de COT simulados e medidos foram de $-0,17,-3,64$ e 4,46\% respectivamente para PC, PD e PIN, todos dentro do limite do erro padrão da média calculado para os valores medidos. Esses resultados mostram o grande potencial do modelo em simular de forma adequada os estoques de COT no solo para ambientes tropicais, corroborando com os resultados encontrados em outros trabalhos (LEITE et al., 2004a; LEITE et al., 2004b; LIANG et al., 1996).

Em relação aos compartimentos, o Century também simulou valores próximos dos medidos. A maior diferença entre os valores medidos e simulados não passou de $-25 \%$ no compartimento ativo para o PD. Como o tamanho do compartimento ativo é muito flutuante durante o ano, essa diferença é justificável, ainda mais porque a coleta de solo foi feita numa época de pouca umidade, fazendo com que no campo o tamanho desse compartimento seja reduzido. Cabe ressaltar que o valor do C ativo simulado é reflexo da média do ano e não de uma determinada condição diária de coleta de solo. Para os demais tratamentos, os estoques dos compartimentos ativos foram semelhantes. Esses resultados foram mais próximos dos observados do que os obtidos em outros trabalhos realizados no mesmo Estado (LEITE et al., 2004a; LEITE et al., 2004b), onde esses estoques foram superestimados pelo modelo, em mais de $100 \%$.

Para o compartimento lento, o modelo simulou valores muito próximos da realidade, sendo 11; 12 e $-5 \%$ diferente dos valores medidos para PC, PD e PIN, respectivamente.

No que se refere ao compartimento passivo, somente para o PIN esses valores ficaram fora (maiores) do limite do erro padrão da média, no entanto a diferença foi menor do que $6 \%$. Resultados semelhantes foram obtidos por Leite et al. (2004a) e Leite et al. (2004b), sendo os valores simulados muito próximos dos medidos, evidenciando a capacidade do Century em simular corretamente esse compartimento.

Comparando os resultados para N (Tabela 4), o modelo não apresentou o mesmo desempenho em relação ao C. Para NT, os estoques foram superestimados em 11; 8 e $29 \%$ para PC, PD e PIN, respectivamente. Para o PIN o valor foi muito acima do observado, sendo que para os demais tratamentos, os valores simulados não apresentaram discrepâncias muito grandes, mesmo que ainda esteja fora do limite do erro padrão da média. Para o compartimento passivo, o comportamento foi muito semelhante ao NT, uma vez que esse compartimento representa mais de $90 \%$ do NT. 
Tabela 4 - Comparação entre os valores simulados e os obtidos no campo via métodos laboratoriais para carbono orgânico total (COT) e nitrogênio total (NT) nos compartimentos ativo, lento e passivo para o plantio convencional (PC), plantio direto (PD) e Pinus (PIN), em Sete Lagoas/MG

\begin{tabular}{cccccc}
\hline \multirow{2}{*}{$\mathrm{T}$} & \multirow{2}{*}{ Compartimentos } & \multicolumn{2}{c}{ Estoques de COT $\left(\mathrm{Mg} \mathrm{ha}^{-1}\right)$} & \multicolumn{2}{c}{ Estoques de NT $\left(\mathrm{Mg} \mathrm{ha}^{-1}\right)$} \\
\cline { 2 - 6 } & & Simulado & Medido & Simulado & Observado \\
\hline \multirow{3}{*}{ PC } & Ativo & 0,79 & $0,79(0,08)$ & 0,21 & $0,12(0,01)$ \\
& Lento & 1,73 & $1,54(0,07)$ & 0,52 & $0,05(0,01)$ \\
& Passivo & 45,70 & $45,96(1,10)$ & 3,16 & $3,32(0,10)$ \\
& Total & 48,21 & $48,29(1,16)$ & 3,90 & $3,50(0,11)$ \\
\hline \multirow{3}{*}{ PD } & Ativo & 0,98 & $0,79(0,06)$ & 0,28 & $0,13(0,01)$ \\
& Lento & 2,37 & $2,11(0,06)$ & 0,73 & $0,08(0,01)$ \\
& Passivo & 46,38 & $48,71(2,45)$ & 3,21 & $3,69(0,11)$ \\
& Total & 49,73 & $51,61(2,48)$ & 4,22 & $3,90(0,12)$ \\
\hline \multirow{3}{*}{ PIN } & Ativo & 0,83 & $0,85(0,04)$ & 0,05 & $0,11(0,01)$ \\
& Lento & 3,74 & $3,95(0,21)$ & 0,18 & $0,15(0,01)$ \\
& Passivo & 45,95 & $43,56(1,00)$ & 3,16 & $2,36(0,07)$ \\
& Total & 50,52 & $48,36(1,10)$ & 3,39 & $2,62(0,06)$ \\
\hline
\end{tabular}

${ }^{1}$ Valores entre parênteses referem-se ao erro padrão da média

As maiores discrepâncias para $\mathrm{N}$ foram nos compartimentos ativo e lento. Para o compartimento ativo, o modelo superestimou os valores em torno de $100 \%$ para as culturas anuais e para o PIN. Esses resultados reforçam a necessidade de mais ajustes no modelo para simular de forma mais adequada esse compartimento de N. Já para o compartimento lento, os estoques foram superestimados para as culturas anuais e muito próximos para o PIN.

\section{Simulação de cenários futuros}

Nas Figuras 3 e 4 são apresentadas as dinâmicas dos estoques de COT, NT e compartimentos ativo, lento e passivo para o PIN até o ano de 2100.

Foram simulados 3 cenários, sendo o primeiro (PINa) a continuação do manejo dado ao PIN até o ano de 2004, simulando um corte a cada 30 anos. Nesta situação, os estoques de COT mostraram um leve aumento com o passar dos anos, e para NT, esse aumento foi mais acentuado. A cada evento de colheita da madeira, os estoques de COT e NT são afetados, apresentando um rápido aumento seguido de diminuição acentuada, que após 30 anos é recuperada. Esse comportamento é explicado pela adição de material vegetal da parte aérea que fica no campo após a colheita da madeira. Esse cenário não mostrou grandes alterações em relação ao PINa, uma vez que o preparo somente era utilizado nos primeiros anos. Embora os compartimentos ativo e lento fossem pouco afetados, o passivo apresentou melhora em seus estoques.
No terceiro cenário simulou-se a redução do número de eventos de fogo (PINc), que antes aconteciam bianualmente e passam a ocorrer duas vezes durante cada ciclo de 30 anos. Esse cenário foi o que apresentou a melhor resposta para melhoria dos estoques de $\mathrm{C}$ e $\mathrm{N}$ no solo.Os estoques de COT e $\mathrm{C}$ lento passaram a ser maiores aos encontrados no Cerrado. Para o C lento, os estoques ainda não superaram o Cerrado, mas apresentaram grandes aumentos. $\mathrm{O} \mathrm{C}$ passivo mostra que a única forma de aumentar seus estoques é evitando queimadas. Apesar da falta de consistência dos dados de $\mathrm{N}$ simulados pelo modelo Century, o comportamento geral não foi alterado na simulação. Em relação ao $\mathrm{N}$, somente o $\mathrm{N}$ ativo ainda não supera os estoques observados no Cerrado.

Já para $\mathrm{PC}$ e $\mathrm{PD}$, os cenários futuros foram simulando o uso de monocultivo de milho (PDa e PCa) e cultivos alternados de milho e soja (PDb e PCb) (Figuras 5 e 6).

O uso de monocultivo é mais impactante do que o uso de cultivos alternados de milho e soja. No caso do COT, para o PDb, os estoques se igualam aos do Cerrado, muito diferente do que ocorre para PDa, PCa e PCb, onde há redução nos estoques. Em relação ao C passivo, somente PDa apresentou potencial para melhorar os estoques até o ano de 2100. Muito semelhante ao C, foram os comportamentos da dinâmica dos estoques de N. Tanto para NT e compartimentos, o melhor cenário criado foi usando alternância de culturas em sistema de plantio direto (PDa), evidenciando a necessidade de evitar 
Figura 3 - Variação dos estoques de nitrogênio total (NT) e compartimentos passivo (N passivo), lento (N lento) e ativo ( $\mathrm{N}$ ativo) estimados pelo modelo Century v4.5 para o PINUS; (PINa) com preparo e queimada, (PINb) sem preparo e com queimada, (PINc) sem preparo e somente duas queimadas por ciclo, em Sete Lagoas/MG
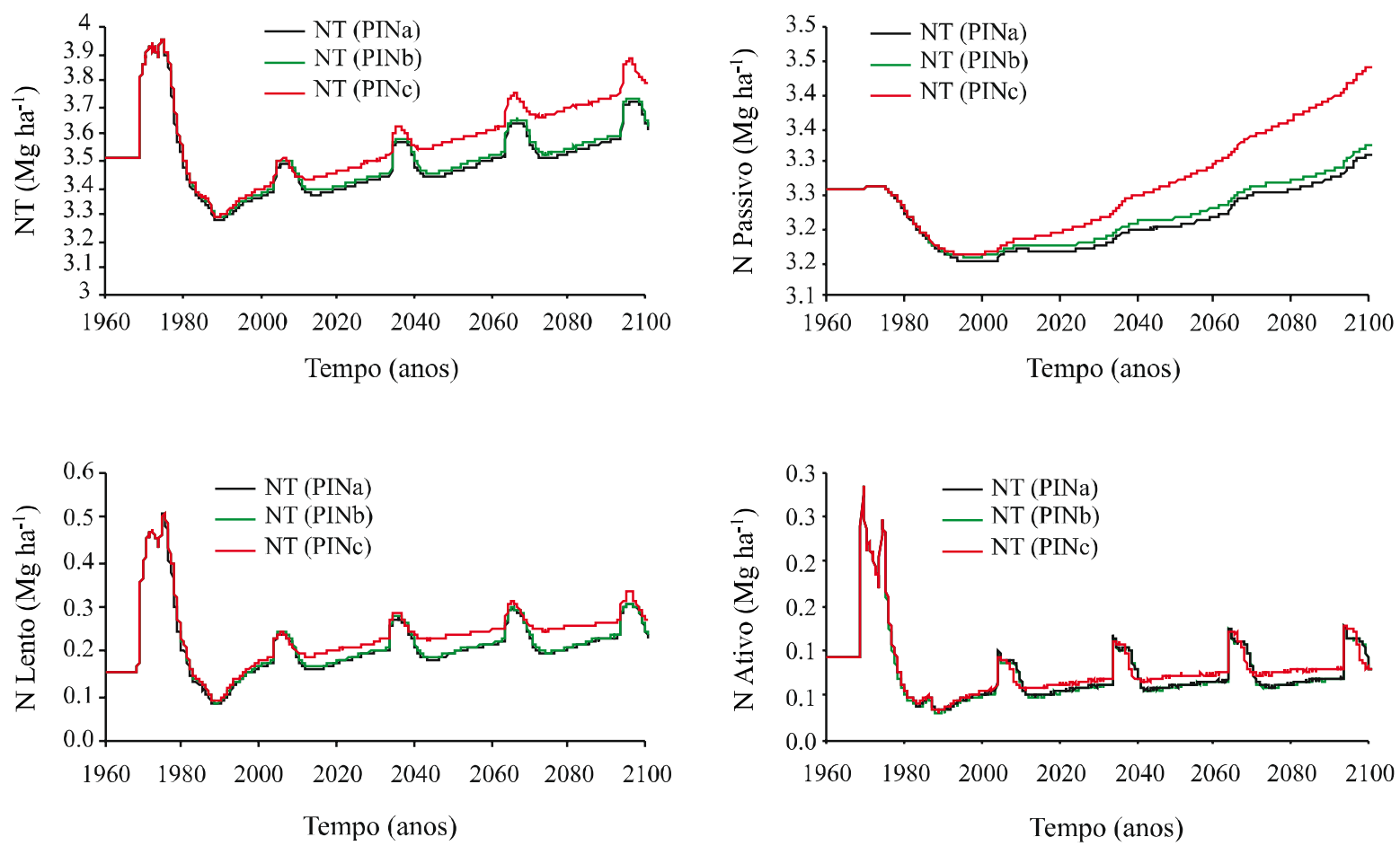

Figura 4 - Variação dos estoques de carbono orgânico total (COT) e compartimentos passivo (C passivo), lento (C lento) e ativo (C ativo) estimados pelo modelo Century v4.5 para o PINUS; (a) com preparo e queimada, (b) sem preparo e com queimada, (c) sem preparo e somente duas queimadas por ciclo, em Sete Lagoas/MG
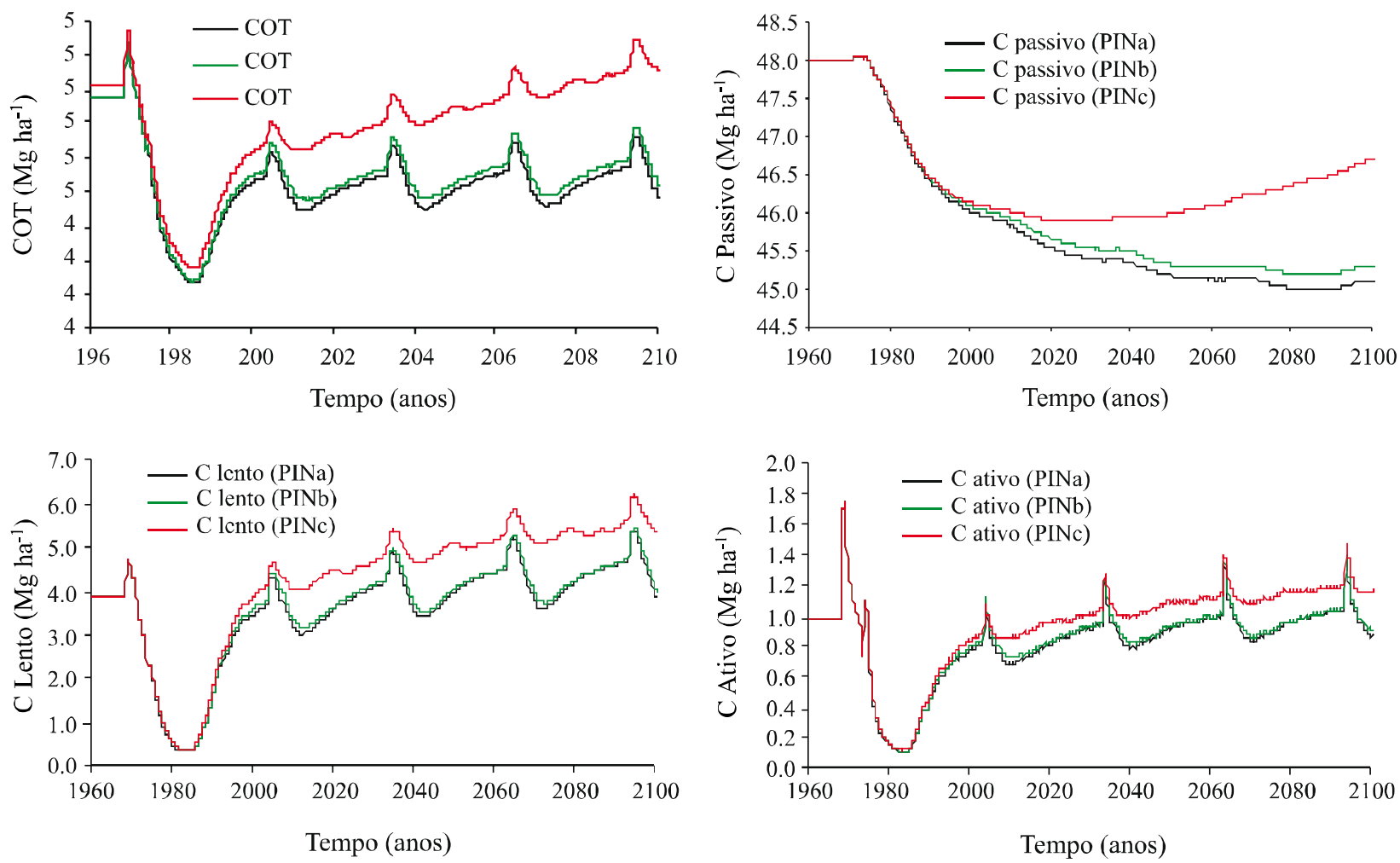
Figura 5 - Variação dos estoques de nitrogênio total (NT) e compartimentos passivo (N passivo), lento (N lento) e ativo (N ativo) estimados pelo modelo Century v4.5 para os tratamentos plantio convencional (PC) plantio direto (PD); (a) milho sem rotação, (b) rotação milho/soja, em Sete Lagoas/MG
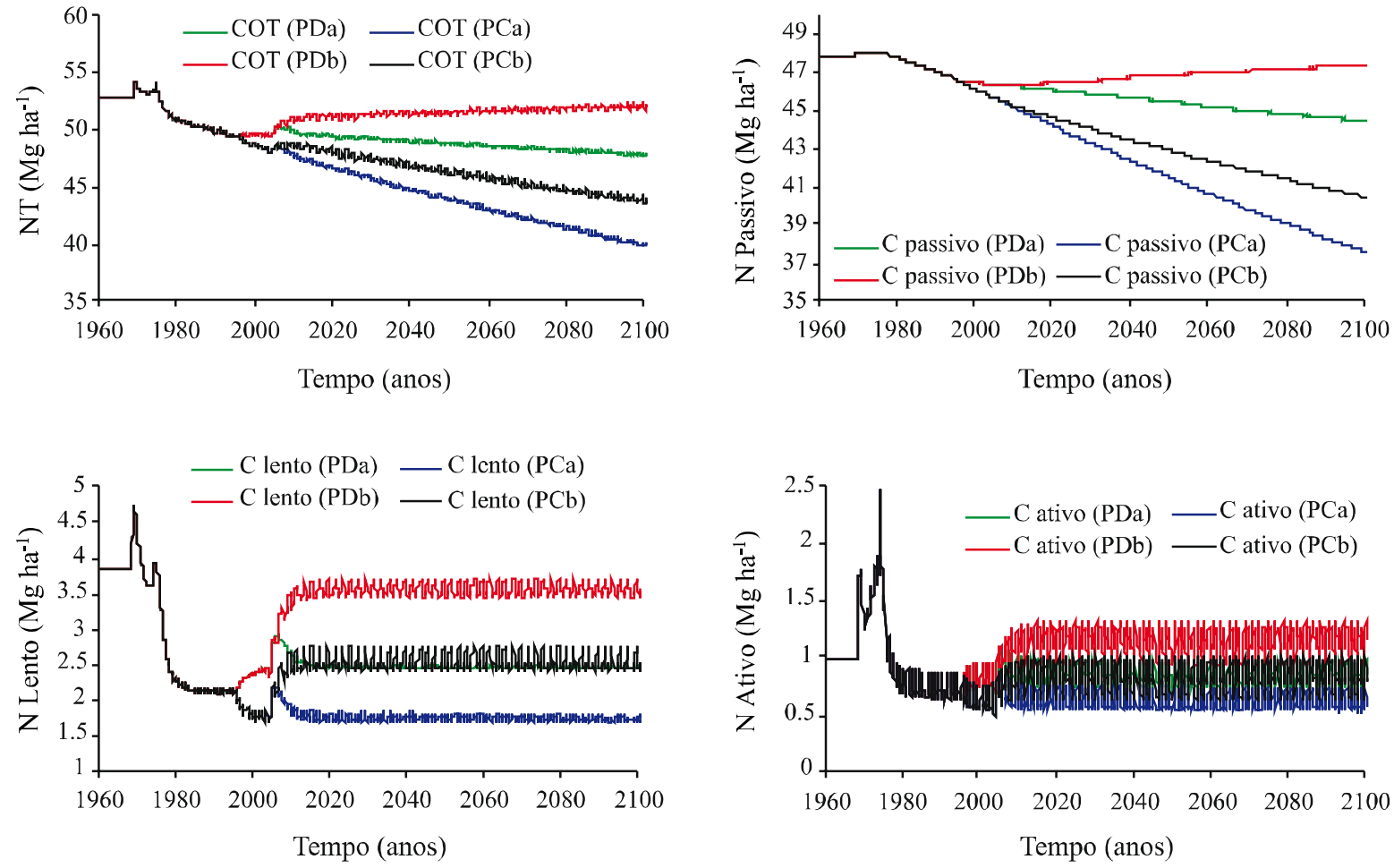

Figura 6 - Variação dos estoques de carbono orgânico total (COT) e compartimentos passivo (C passivo), lento (C lento) e ativo (C ativo) estimados pelo modelo Century v4.5 para os tratamentos plantio convencional (PC) plantio direto (PD); (a) milho sem rotação, (b) rotação milho/soja, em Sete Lagoas/MG
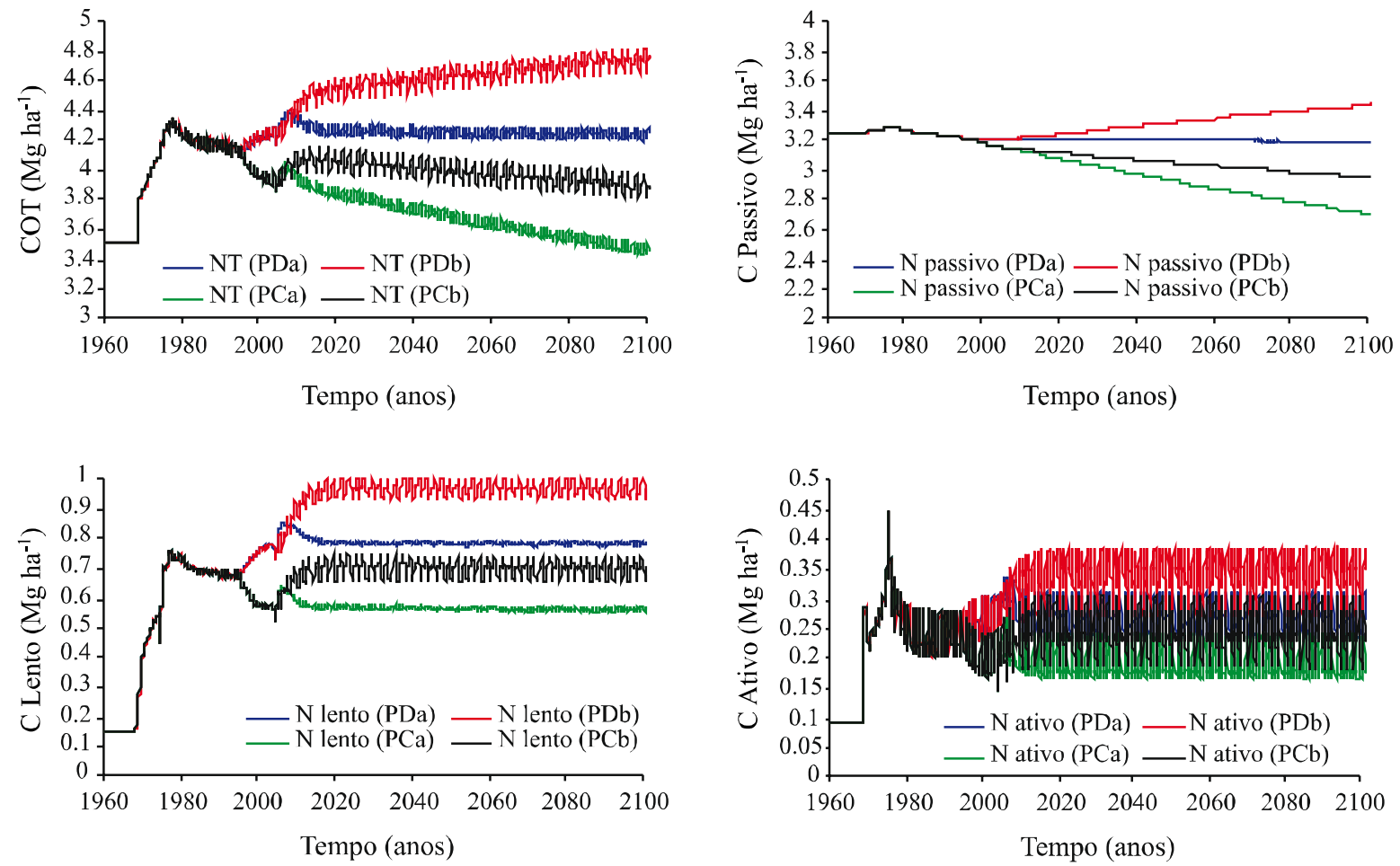
o revolvimento do solo e o monocultivo como alternativas para melhoria dos estoques de $\mathrm{N}$ no solo.

\section{CONCLUSÃO}

O modelo Century é sensível às mudanças de manejo adotadas no Cerrado brasileiro, sendo os compartimentos mais lábeis, mais sensíveis (ativo e lento) do que o mais estável (passivo). Os estoques simulados pelo Century refletiram os medidos, ou seja, o modelo tem validade, no entanto, para $\mathrm{N}$, os compartimentos não apresentam ajuste tão satisfatório como para $\mathrm{C}$, necessitando ainda de melhorias no modelo. Deve ser dada importância ao plantio direto em relação ao preparo convencional nessa região, uma vez que esse apresenta maior potencial para manter ou recuperar o $\mathrm{C} \mathrm{e} \mathrm{N}$ do solo. Os cenários futuros mostram a importância de se evitar queimadas e monocultivo de milho, dando preferência aos cultivos alternados de milho e soja.

\section{AGRADECIMENTOS}

Os autores agradecem à Empresa Brasileira de Pesquisa Agropecuária - EMBRAPA/CNPMS, pela concessão da área de estudo; ao $\mathrm{CNPq}$, à CAPES, à FAPEMIG, e ao Departamento de Solos/UFV, pelo apoio financeiro. Ao grupo do National Resource Ecology Laboratory, Universidade do Colorado State, pelo apoio com a simulação do modelo Century.

\section{REFERÊNCIAS}

BROOKES, P. C. et al. Chloroform fumigation and the release of soil nitrogen: a rapid direct extraction method to measure soil microbial biomass nitrogen in soil. Soil Biology Biochemistry, v. 17, p. 837-842, 1985.

CAMBARDElla, C. A.; ElliotT, E. T. Carbon and nitrogen dynamics of soil organic matter fractions from cultivated grassland soil. Soil Science Society America Journal, v. 58, p. 123-130, 1994.

CERRI, C. E. P. et al. Modeling soil carbon from forest and pasture ecosystems of Amazon, Brazil. Soil Science Society America Journal, v. 67, p. 1879-1887, 2003.

FERNANDES, F. F. Uso do modelo Century para o estudo da dinâmica de carbono orgânico de solos do Rio Grande do Sul. 159f, 2002 Tese (Doutorado em Ciência do Solo), Programa de Graduação em Ciência do Solo, Universidade Federal do Rio Grande do Sul, Porto Alegre. 2002.

HARRISON, K. G.; POST, W. M.; RICHTER, D. D. Soil carbon turnover in a recovering termperate forest. Global Biogeochemical Cycles, v. 9, p. 449-454, 1995.
ISLAM, K. R.; WEIL, R. R. Microwave irradiation of soil for routine measurement of microbial biomass carbon. Biology and Fertility Soils, v. 27, p. 408-416, 1998.

LEITE, L. F. C. et al. Simulating trends in soil organic carbon of an Acrisol under no-tillage and disc-plow systems using the Century model. Geoderma, v. 120, p. 679-686, 2004a.

LEITE, L. F. C. et al. Simulação pelo modelo Century da dinâmica da matéria orgânica de um argissolo sob adubação mineral e orgânica. Revista Brasileira de Ciência do Solo, v. 28 , n. 2 , p. $347-358,2004$ b.

LEITE, L. F. C.; MENDONÇA, E. S. Modelo century de dinâmica da matéria orgânica do solo: Equações e pressupostos. Ciência Rural, v. 33, n. 4, p. 679-686, 2003.

LOBEL, I.; AMELUNG, W.; DU PREEZ, C. C. Losses of carbon and nitrogen with prolonged arable cropping from sandy soils of the South African Highveld. European Journal of Soil Science, v. 52, p. 93-101, 2001.

LIANG, B. C.; GREGORICH, E. G.; MACKENZIE, A. F. Modeling of organic and inorganic amendments on organic matter in Quebec soil. Soil Science, v. 161, p.109-114, 1996.

PARTON, W. J. et al. Analisys of factors controlling soil organic matter levels in great plais grasslands. Soil Science Society America Journal, v. 51, p. 1173-1179, 1987.

ROMANYA, A. J. et al. Modelling change in soil organic matter after planting fast-growing Pinus radiata on Mediterranean agricultural soils. European Journal of Soil Science, v. 51, p. 627-641, 2000.

SILVA, I. R.; MENDONÇA, E. S. Matéria orgânica do solo. In: NOVAIS, R. F. et al. Fertilidade do solo. Viçosa: SBCS, p. 275-356, 2007.

SIX, J. et al. Stabilization mechanisms of soil organic matter: Implications for C-saturation of soils. Plant and Soil, v. 241, p. 155-176, 2002.

SPARLING, G. P.; WEST, A.W. A direct extration method to estimate soil microbial C: Calibration in situ using microbial and ${ }^{14} \mathrm{C}$ labelled cells. Soil Biology \& Biochemistry, v. 20, p. 337-343, 1988.

STEVENSON, F. J. Humus chemistry: genesis, composition, reactions. Second edition ed. John Wiley \& Sons, 1994.

TEDESCO, M. J. et al. Análise de solo, plantas, e outros materiais. Universidade Federal do Rio Grande do Sul, Porto Alegre, 174 p. 1995.

WENDLING, B. Carbono e Nitrogênio no solo sob diferentes usos e manejos e sua modelagem pelo Century. 2007. 132f. Tese (Doutorado em Solos e Nutrição de Plantas). Universidade Federal de Viçosa, Viçosa, 2007.

YEOMANS, J. C, BREMNER, L. M. A rapid and precise method for routine determination of organic carbon in soil. Communication in Soil Science and Plant Analisys, v. 19, p. 1467-1476, 1988. 